$\begin{array}{cc}1 \text { Laguna de Las Tres Pascualas, } & \text { 4 Pabellón del Instituto de } \\ \text { Concepción } & \text { Química de la Universidad } \\ \text { de Concepción; arquitecto } & \text { Emilio Duhart, 1961 } \\ 2 \text { Plano de emplazamiento } & 5 \text { Estación de trenes de } \\ \text { Concepción. Fachada hacia el } \\ \text { Puente abandonado de } \\ \text { ferrocarriles, VII Región } \\ \begin{array}{l}\text { Bío en su estado actual; } \\ \text { arquitecto Luis Herrera, 1941 }\end{array}\end{array}$

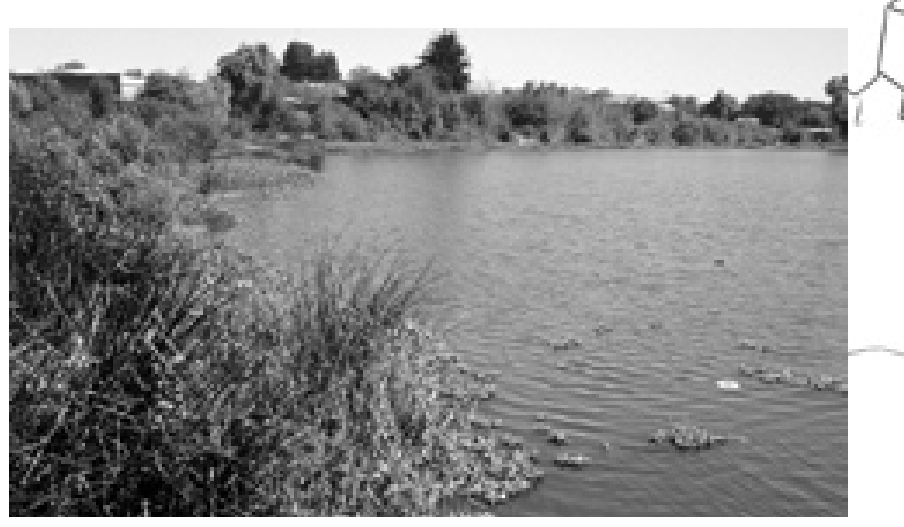

Smiljan Radic + Eduardo Castillo

+ Ricardo Serpell

Texto: Smiljan Radic

Resultado de un concurso público, mostramos en detalle el desarrollo del proyecto para el Barrio Cívico de Concepción. Un proyecto planteado como central dentro de la renovación urbana de esta ciudad propuesta por el Plan Concepción. Este edificio, tanto por sus dimensiones como por su calidad arquitectónica, debiera constituirse como una de las grandes obras de la arquitectura promovida por el Estado durante este siglo.

Palabras clave: Barrio cívico, arquitectura-Concepción, concursos de

arquitectura, edificios de oficinas.

We show bere in detail the development of a project for Concepción's Civic quarter, resulting from a public architectural competition. This project is considered to be of central importance in the context of this city's urban renewal, as it is proposed by the "Plan Concepción". This building, both by its dimensions and by its architectural quality, should become one of the greatest architectural works brought about by the Chilean state in this century. Keywords: Civic quarter, architecture-Concepción, architectural competitions,

\section{Barrio Cívico, Concepción}

El año 2001 nuestro proyecto obtuvo el primer premio en un concurso nacional de arquitectura convocado por la Dirección de Arquitectura del M.O.P. Después de eso, el proyecto fue desarrollado a lo largo de 330 días corridos de trabajo. 16 horas diarias. 270 láminas de arquitectura.

1. La geografía en torno a Concepción tiene una estrecha relación con el agua, marcada por el paso del río Bío Bío, que frente a la ciudad tiene un ancho de 1,5 a $2 \mathrm{~km}$, y por numerosas lagunas como las Tres Pascualas, las de San Pedro, las de Lo Galindo y la Redonda, que dan cuenta de la cercanía del nivel del mar y las lluvias predominantes.

2. El plan regulador de 1960 desarrollado por Emilio Duhart proponía entre sus puntos más relevantes la recuperación de la ribera norte del río Bío Bío y ubicaba una isla artificial con un nuevo capitolio y centro administrativo regional en medio de su caudal.

El seccional vigente para la zona del proyecto sitúa una pieza urbana con programa similar al propuesto por Duhart; esta vez en un punto intermedio entre la ciudad histórica, a la cual la Estación de Ferrocarriles hace frente, y la futura ciudad (aún baldía) ubicada a sus espaldas.
3. Entre los años ' 40 y finales de los '60 del s.XX Concepción se convirtió en un importante referente urbano, gracias a la arquitectura moderna que reconstruyó la ciudad después de los terremotos de 1939 y 1960. La Estación de Ferrocarriles es uno de los primeros ejemplos de arquitectura proto-moderna en la ciudad.

Durante este período la arquitectura siguió en parte (o por lo menos en aquella parte que nos gusta mirar) un plan basado en un lenguaje con constantes proyectuales que constituyen un notable acierto para la ciudad. Estos aciertos proponen una integración entre paisaje y edificación a través de espacios exteriores cubiertos por volúmenes, porticados, corredores techados y graderías que responden a una escala urbana y no sólo a las necesidades inmediatas de sus edificios; volúmenes relativamente simples, donde la materialidad de revestimientos y estructuras vistas es protagónica; una tentación por integrar arte y arquitectura, donde algunos edificios o parte de ellos son usados como soporte político para obras de arte convencionales (murales, esculturas de plinto, etc.); el uso de un sistema de organización abierta en instituciones públicas, evitando tipologías de edificación en torno a patios cerrados, tipo mall comercial, o volúmenes enjaulados. 

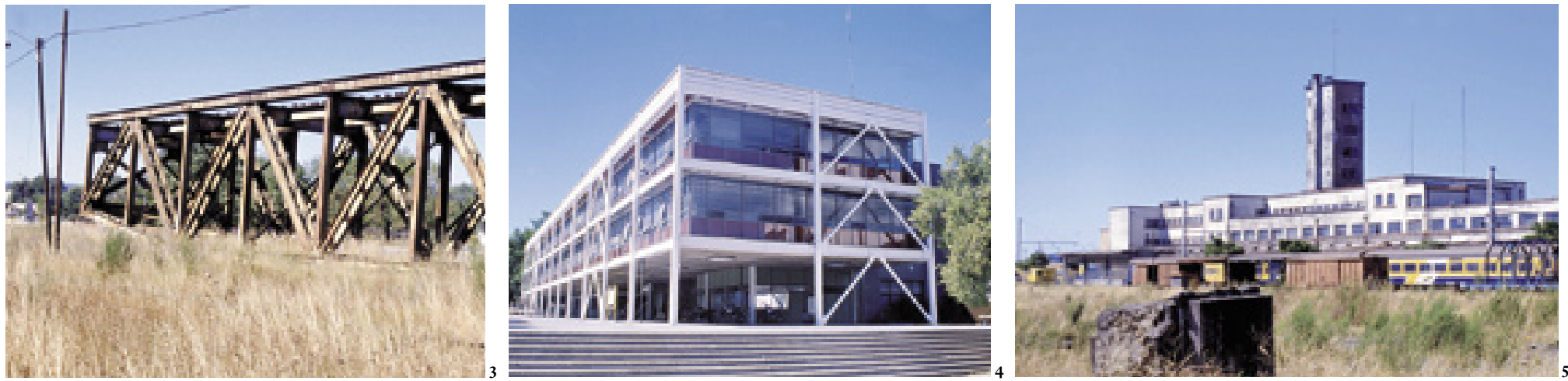

4. La modernización del Estado necesariamente implica una mayor eficiencia en el uso de lo que se ha llamado el "tamaño del Estado". La discusión sobre el tamaño dentro de ciertos márgenes al parecer importa poco, no así su uso eficiente, idea tras la cual derechas e izquierdas de nuestro país se enrielan. Implica a su vez una mayor transparencia y descentralización en la toma de decisiones, una profesionalización de los servicios, una dignificación de los funcionarios, un contacto directo con la comunidad dignamente atendida, una autonomía de los distintos departamentos y a la vez una estrecha interrelación entre ellos como cuerpo unitario. ¿Cuánto de esto tiene que ver con la arquitectura?

Según las políticas de Estado, el gobierno regional no sólo debe ser versátil y tener una gestión contemporánea y transparente sino también debe comunicar esta condición: verse ágil, transparente y contemporáneo.

Su imagen cerrada e impermeable (oscura) debería transformarse de alguna manera en una estructura artificialmente abierta y permeable. Si consideramos esta idea en serio, en cierta medida todos los edificios públicos en Chile serán abiertos, aunque esto sea un artificio, como la apertura al paso de $L a$ Moneda.

Todos los edificios públicos irán obteniendo esta condición para asegurar un rol político efectivo, mientras la ciudad sea pre-metropolitana (como lo es Concepción), o sea, una ciudad en la cual se siga viendo convencionalmente una precisa jerarquía del edificio o "contenedor" que desarrolla la función de cuerpo de referencia, que pone orden y tiempo al total.

En la metrópoli, en cambio, las telecomunicaciones han vaciado estos contenedores de contenido, de lugar y territorio. Su lugar es el que le confinan las rejas, rejas que pueden estar en cualquier parte, y cualquiera significa, para una mirada convencional o nostálgica, ninguna. La metrópoli es una nómada prisionera, como la define Massimo Cacciari.

5. En su aspecto institucional este edificio es una interfaz o un intermediario entre la comunidad regional y el gobierno central. Por otro lado, gracias a su ubicación estratégica parece adecuado pensar el sitio en cuestión como relacionador entre la ciudad nueva al norte del límite impuesto por las líneas de ferrocarriles y la ciudad histórica. Nuestra propuesta urbana propone el sitio como una zona rara que flota entre ciudades, situando la Estación de Ferrocarriles y los edificios que la acompañan en una plataforma o andén urbano, de imagen clara y límites públicamente permeables. Un recuerdo de aquella isla que Duhart pensó flotaría sobre el Bío Bío.

A cada lado de la Estación de Ferrocarriles existirán dos edificios flotantes-compuestos por 4 pabellones cada uno y una placa en los primeros nivelesdispuestos en dirección Río-Ciudad; cada uno de ellos forma un área de proyecto. Estos edificios convierten a la Estación en una pieza única y destacada, acentuando su frontalidad, mientras señalan la nueva dirección de vinculación que el seccional propone incentivar: desde un nivel urbano global hasta la condición peatonal más próxima.

6. El espacio público interesa desde siempre por su capacidad para generar interacción colectiva (vean las grandes explanadas de intercambio precolombinas) o para barrer con ella (vean las intervenciones de Haussman en el París del s.XIX vistas a través de los ojos de Walter Benjamin). En el Barrio Cívico de Concepción intentamos traer al imaginario público situaciones que efectivamente están a la mano en la región, poniéndolas todas dentro de una plataforma urbana accesible.

Se han retomado elementos de la geografía $\mathrm{y}$ vegetación regionales para crear un nuevo lugar artificial, generado por una laguna paralela a la avenida Arturo Prat por debajo de los volúmenes del proyecto y frente a la Estacióón de Ferrocarriles existente. En esta laguna existen dos explanadas de madera de durmientes, una al aire libre frente a la Estación, otra bajo los volúmenes del área 3.

Se han proyectado dos pantallas de arte exteriores, de estructura metálica y membranas de poliéster revestido en P.V.C. Estas estructuras reemplazarán a los porticados existentes frente a la Estación de Ferrocarriles y serán soportes de murales, instalaciones, proyecciones de cine, de publicidad o de campañas políticas. Estas construcciones concluyen el área 1 y la definen como una unidad autónoma.

Junto a ellas una serie de esculturas dispuestas en la laguna y sobre los entablados de durmientes acompañan el recorrido: son grandes bolones de cuatro metros cúbicos de acero dulce, inoxidable y aluminio que alterarán el total de este paisaje.

7. El ex edificio de la Estación de Ferrocarriles se ha ampliado construyendo un cuarto piso, comunicado a través de escaleras de escape con la estructura de las pantallas de arte. Su torre se ha vaciado organizando sus vistas diferenciadas, las cuales terminan en un mirador hacia la ribera norte del Bío Bío antes negada por el edificio. El mural existente en el hall de primera clase será iluminado y se abrirá su gran ventanal hacia la avenida Arturo Prat, permitiendo una nueva visión nocturna del mural desde el espacio público.

8. Sobre este espacio público abierto para cualquier usuario se ubicará una serie de pabellones de 9 × 60 metros de plantas libres, donde se alojará el programa de oficinas de los distintos organismos públicos. Estos pabellones estructurados en metal tendrán fachadas de vidrio de matices de verde y ondulado de aluminio puro tipo mini-wave, además de policarbonato color blanco ondulado en las torres y en las placas de primer y segundo niveles.

9. Es evidente que será difícil concluir 38.000 $\mathrm{m}^{2}$ de edificios públicos. Cada uno de estos edificios fue concebido como un área de proyecto autónoma e interrelacionada a través del espacio público.

Lo importante siempre fue pensar partes teniendo el proyecto global como un organizador de la intención final de construcción, que no necesariamente puede tener la forma que hemos propuesto en cada una de las áreas (forma que sin embargo ha sido proyectada en todos sus detalles). Se trata de olvidarse del proyecto global como un objetivo de vida o muerte, si no pensarlo desde ya como algo posiblemente inconcluso. ARQ 

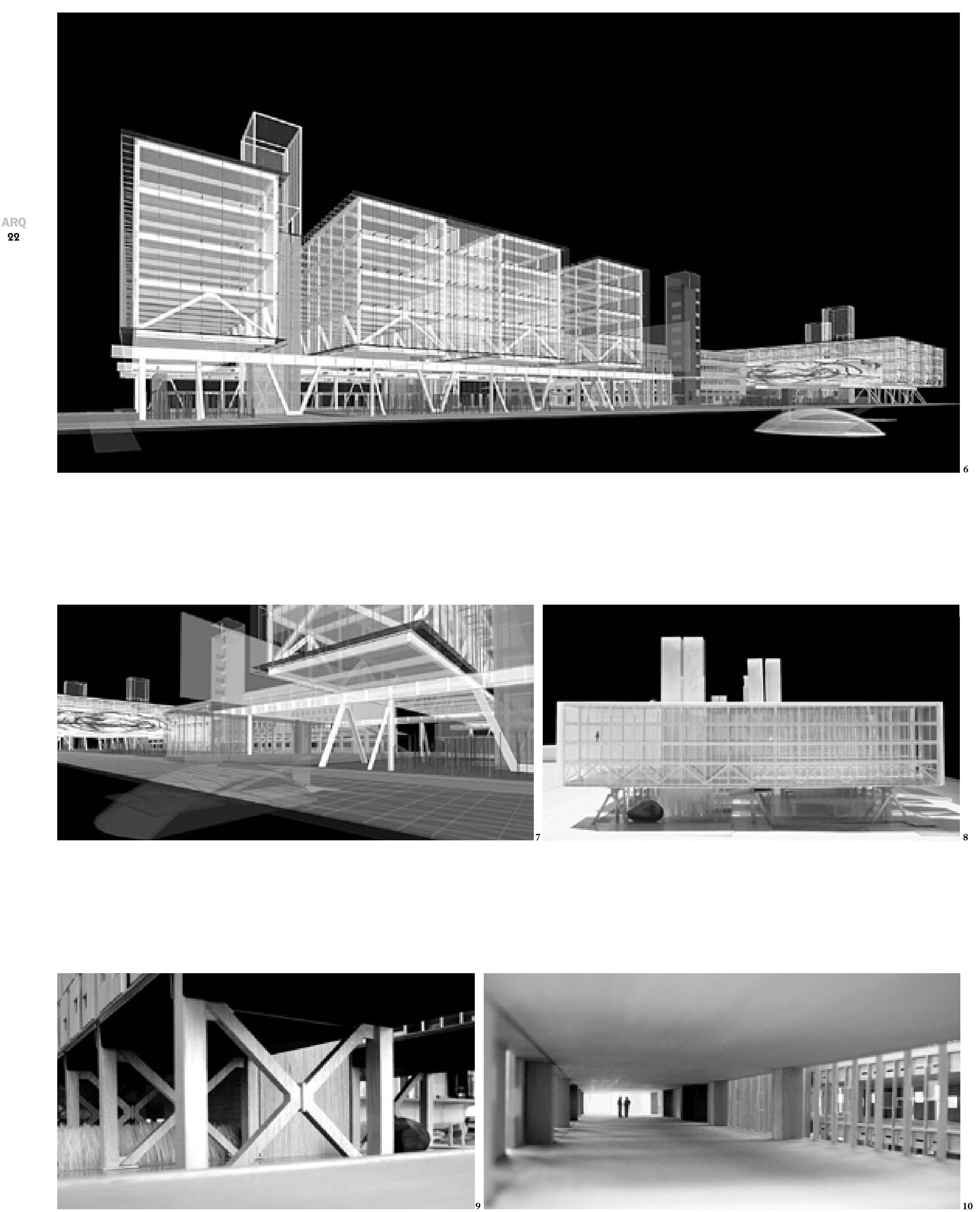
6 y 7 Imágenes de la propuesta el Barrio Cívico de Concepción 8 Maqueta, propuesta del concurso para el Barrio Cívico de Concepción

9 al 12 Maquetas del área $2 \mathrm{~A}$, escala 1.50
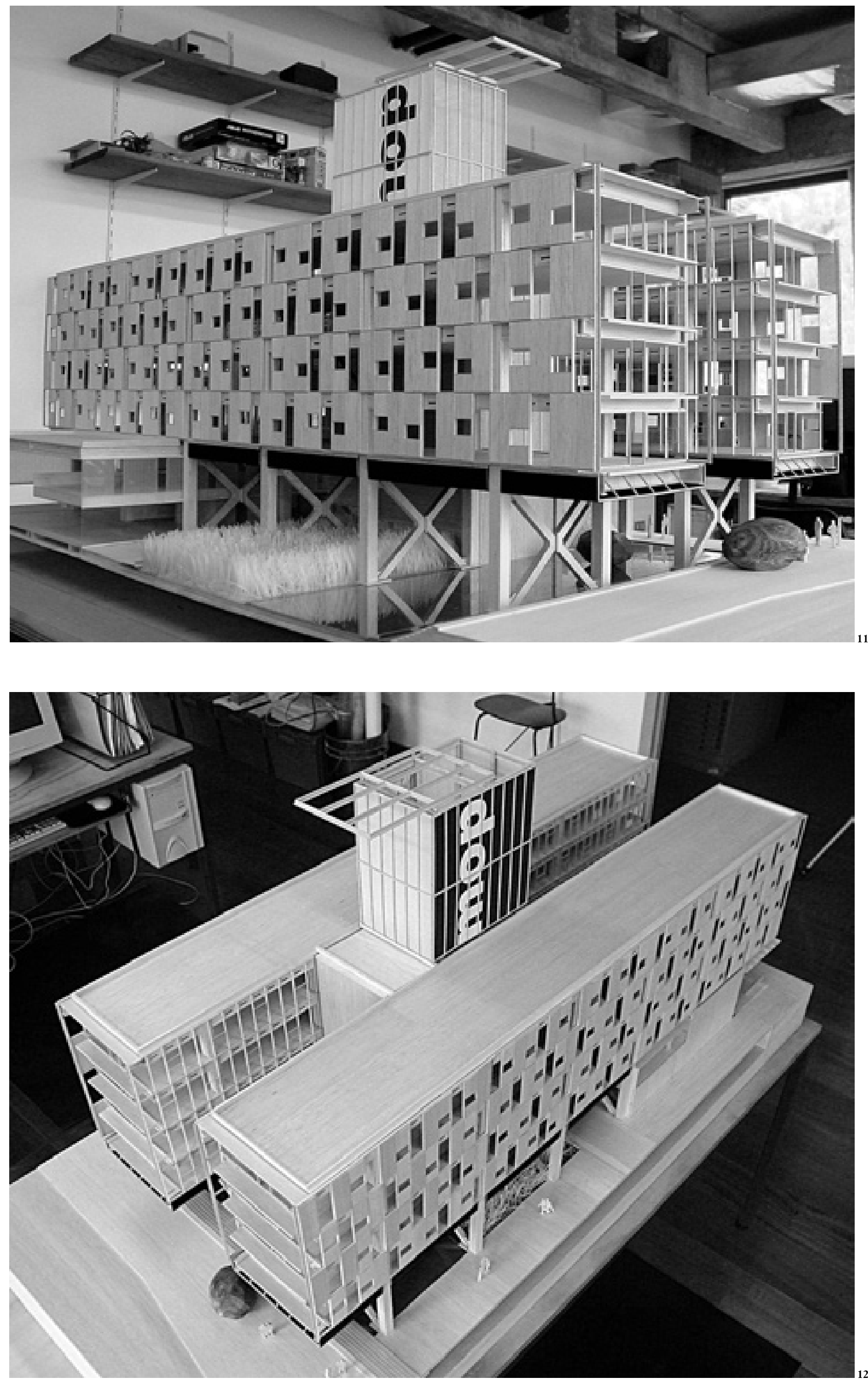


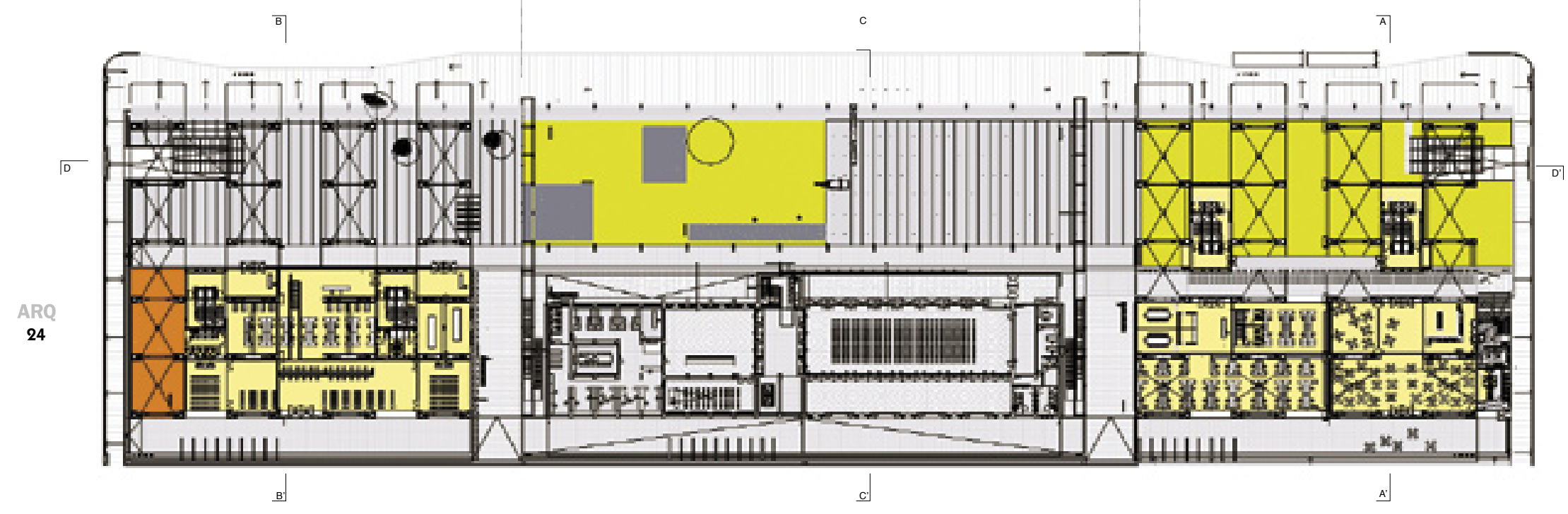

Planta primer nivel -0.12

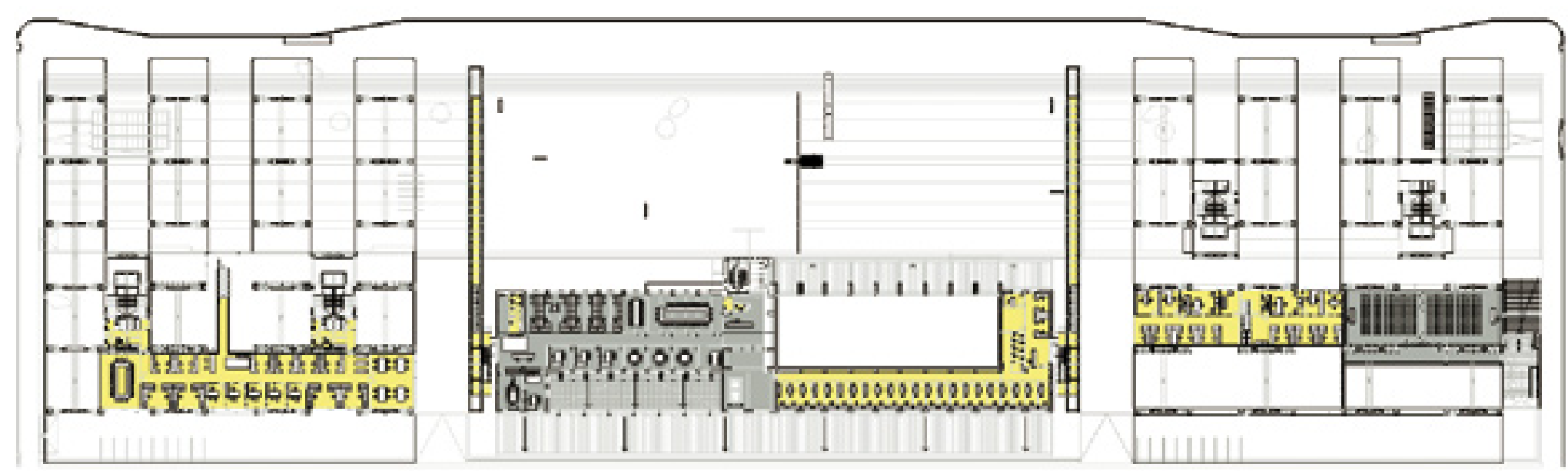

Planta segundo nivel $+3.24 /+5.63$ estación

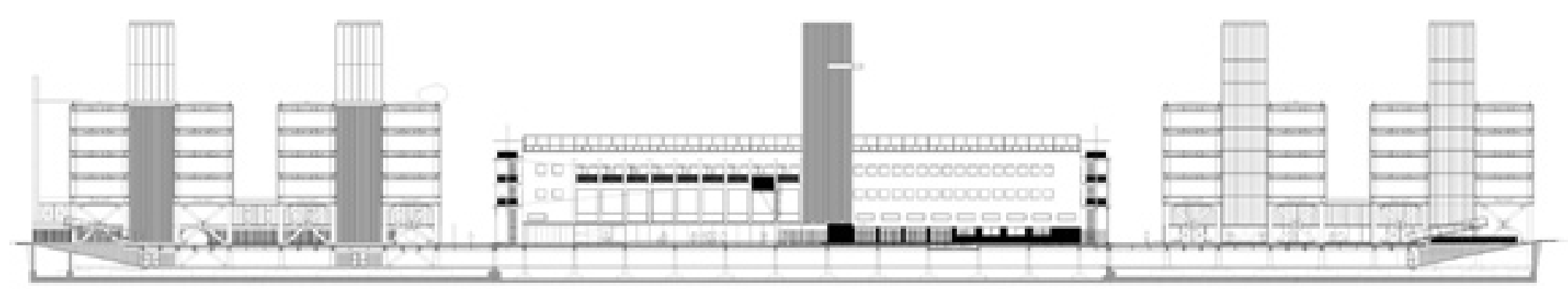



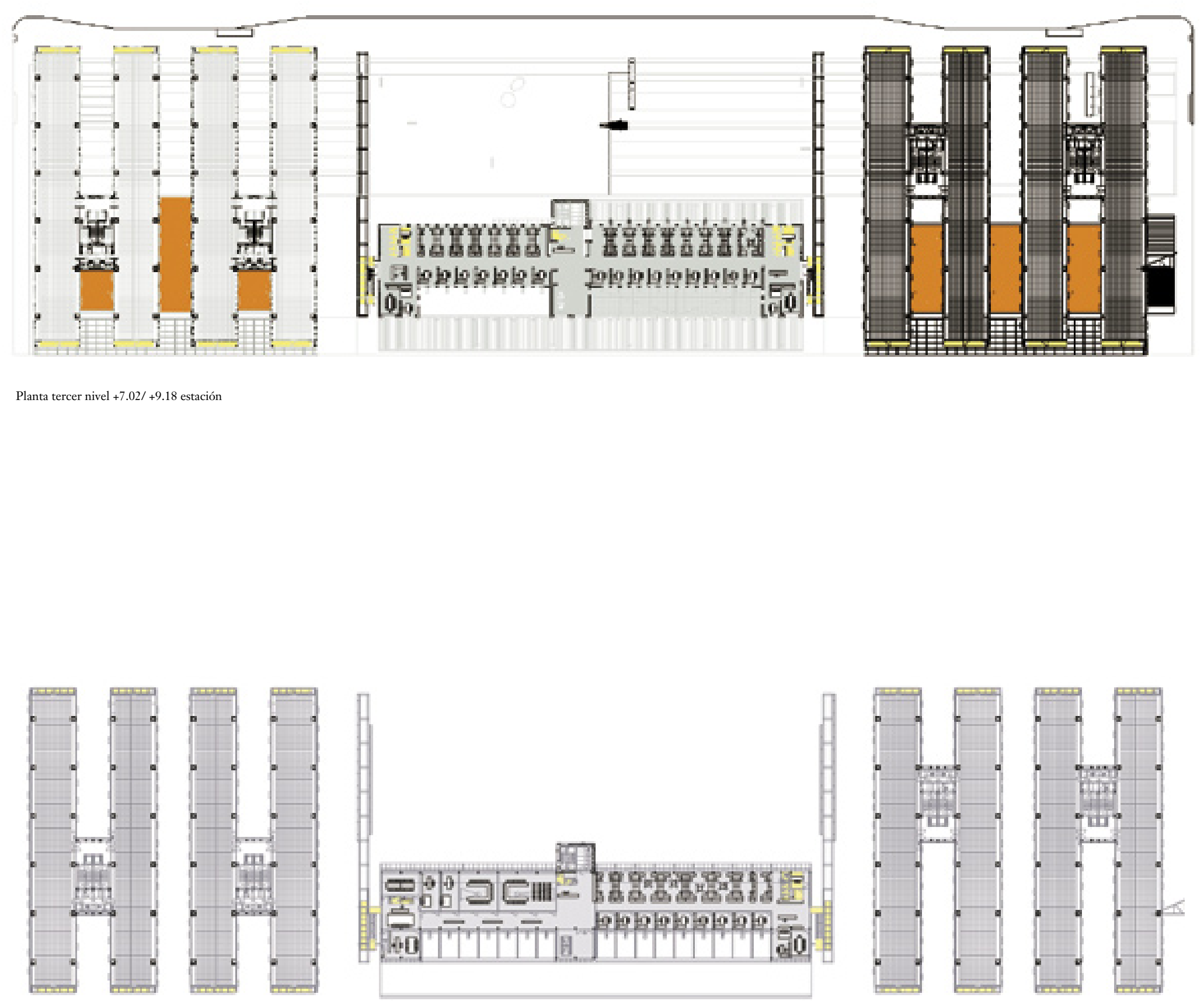

Planta cuarto nivel $+10.44 /+12.73$ estación
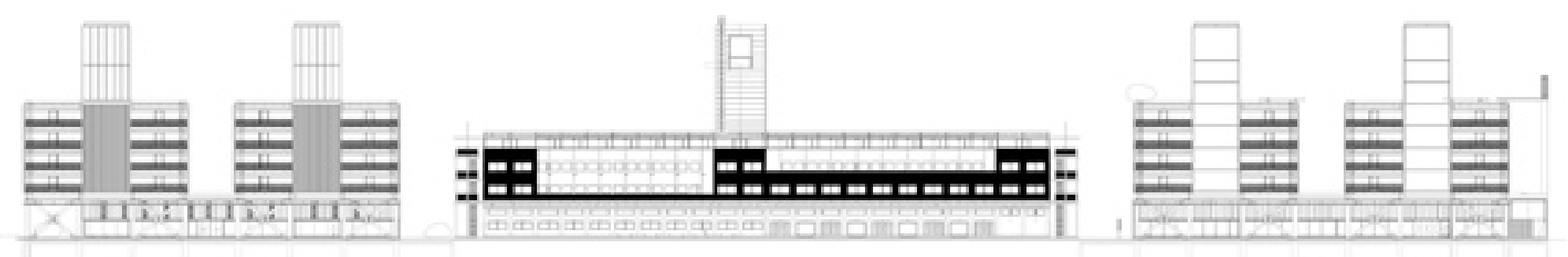


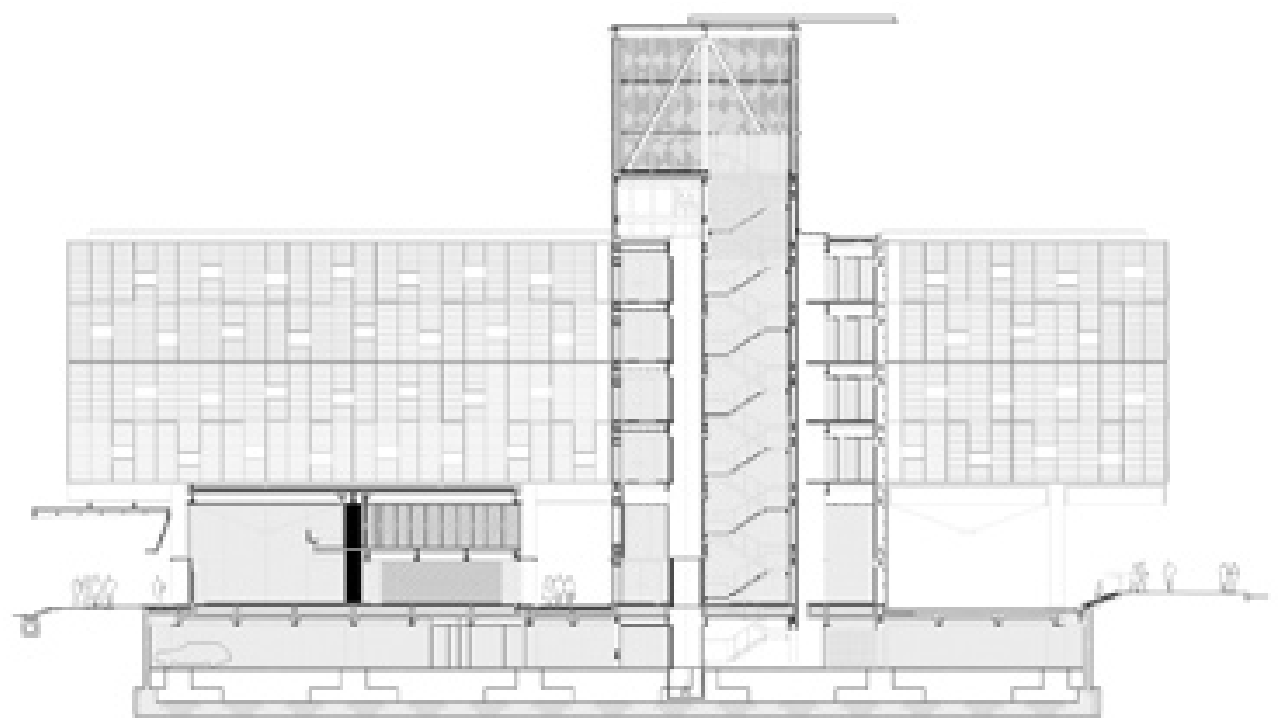

Corte A-A', por núcleo de circulaciones verticales, pabellones de oficinas

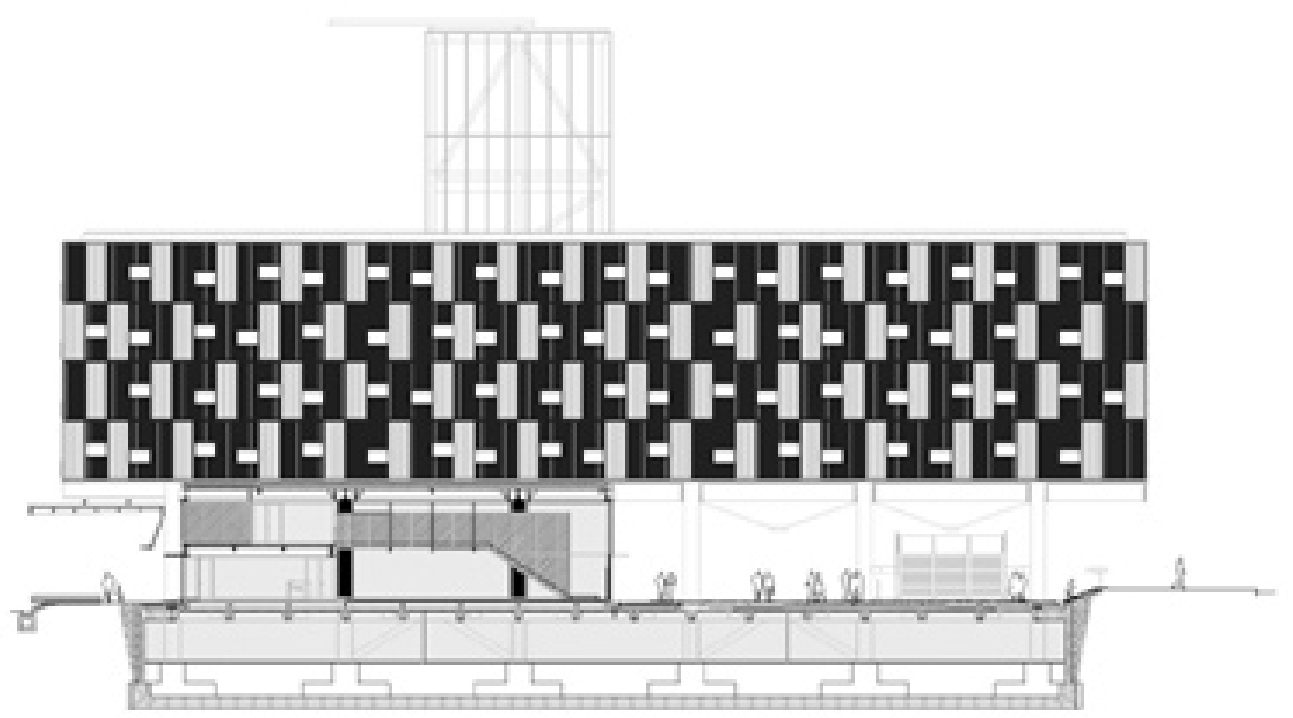

Corte B-B', por acceso a pabellones de oficinas

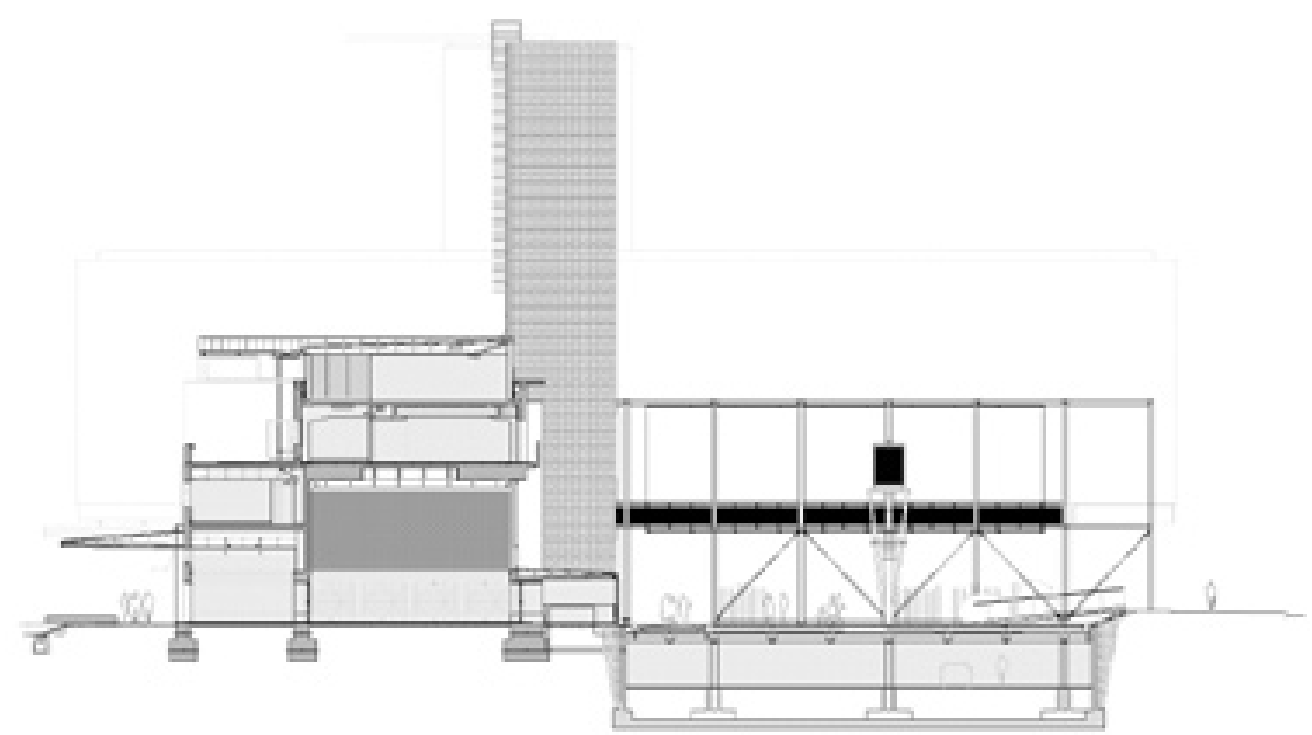



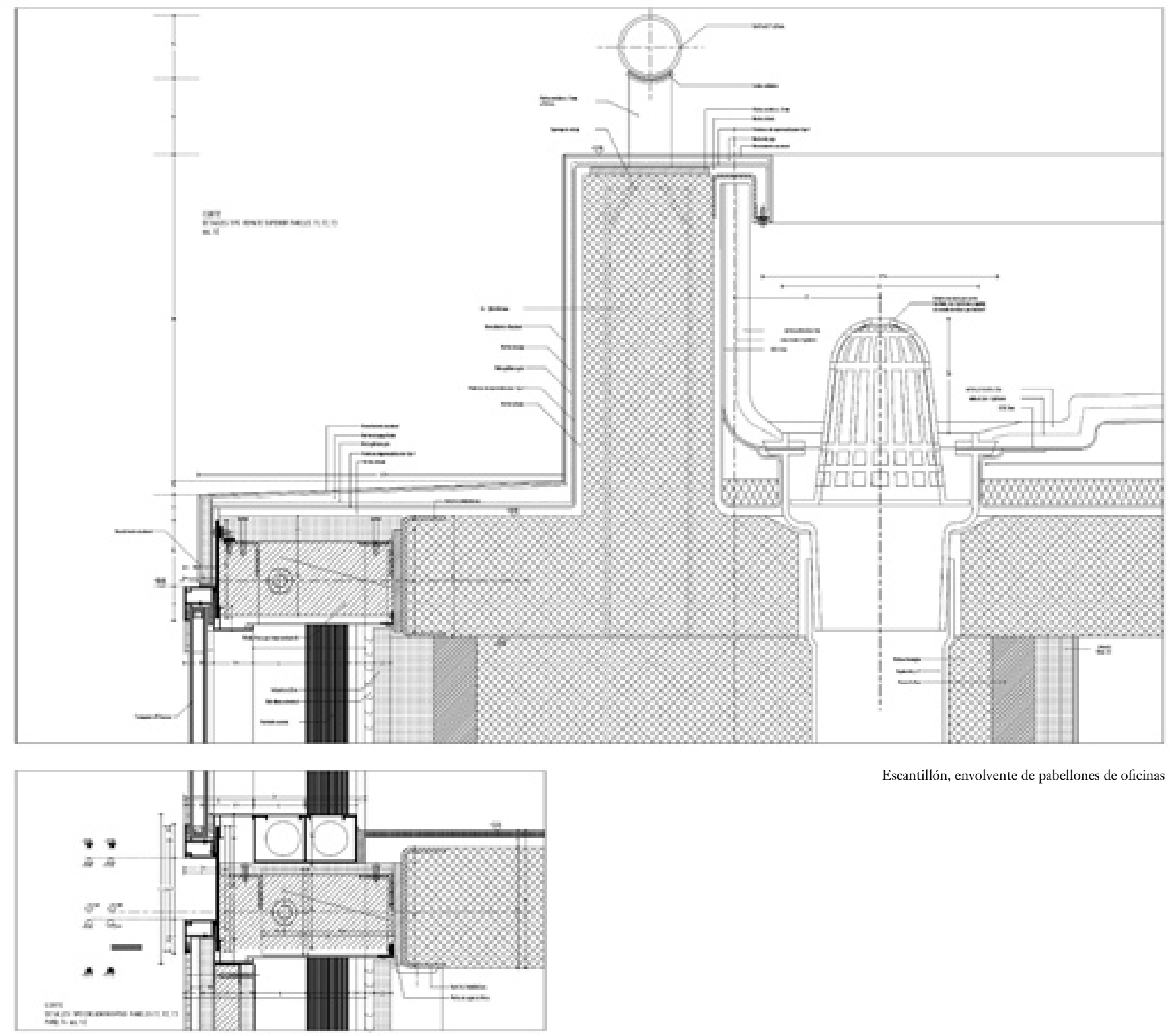

Escantillón, envolvente de pabellones de oficina
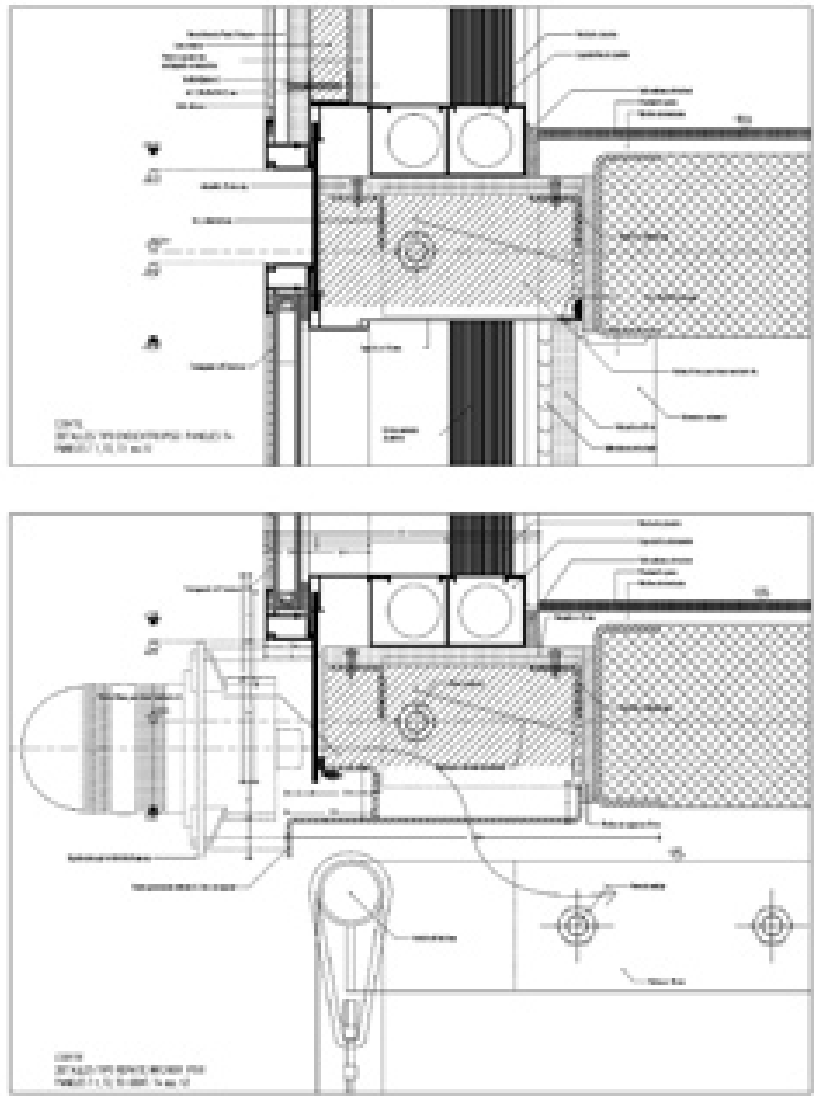

Edificio de Servicios Públicos, Barrio Cívico, Concepción

Arquitectos Smiljan Radic, Eduardo Castillo y Ricardo Serpell Colaboradores María Teresa Covarnubias, Danilo Lascano, Danilo Lagos Ubicación Avenida Arturo Prat 501, Concepción, Chile Mandante Dirección de Arquitectura M.O.P. VIII Región Cálculo estructural SAS Ingeniería Mecánica de suelos EMPRO Ltda. Proyecto instalaciones sanitarias Ing. Patricio Moya Proyecto eléctrico PROINGEL S.A. Proyecto climatización IMPROTERM Ltda. Asesoría acústica ACCURATEK Ltda. Proyecto seguridad PROINGEL S.A. Proyecto iluminación Pascal Chautard Proyecto tratamiento basuras Packer Ingeniería Proyecto cocina casino Arq. Patricio Lagos Proyecto ascensores Thyseen ascensores Informe impacto vial Ingeniero Patricio Peñaloza Revisor independiente IKV arquitectos revisores Proyecto de arte Marcela Correa Materialidad Acero, vidrio, revestimientos metálicos, cerámicos y textiles, pavimentos exteriores de madera y piedra. Superficie terreno $15.446 \mathrm{~m}^{2}$, construida proyectada $38.815 \mathrm{~m}^{2}$ Año concurso 2001, proyecto 2001-2002

Imágenes Smiljan Radic, Eduardo Castillo y Ricardo Serpell 